\title{
Research Review on Professional Development of Preschool Teachers in China
}

\author{
Yuan Qiu${ }^{1}$, Taisheng Fu² \\ ${ }^{1}$ College of Education Science, Gannan Normal University, Ganzhou, China \\ ${ }^{2}$ Jiangxi University Humanities and Social Science Key Research Base Gannan Normal University Educational Economic Research \\ Center, Ganzhou, China \\ Email: ^13824577584@163.com
}

How to cite this paper: Qiu, Y. and Fu, T.S. (2019) Research Review on Professional Development of Preschool Teachers in China. Open Access Library Journal, 6: e5643.

https://doi.org/10.4236/oalib.1105643

Received: July 26, 2019

Accepted: August 10, 2019

Published: August 13, 2019

Copyright $\odot 2019$ by author(s) and Open Access Library Inc.

This work is licensed under the Creative Commons Attribution International License (CC BY 4.0).

http://creativecommons.org/licenses/by/4.0/ (c) (i) Open Access

\begin{abstract}
At present, with the increasing emphasis extent on preschool education in China, preschool education gradually moves from the edge to the center in the entire national education system. And the professional development quality of preschool teachers is the key link and important path for the quality of preschool education development. Take the literatures on the research on professional development of preschool teachers collected by China National Knowledge Infrastructure as samples. The research topics are focused on the four fields of preschool teachers' professional development, including connotation, professional standards, influencing factors and strategies, and making an in-depth analysis of the research status of the professional development of preschool teachers in China. However, at present, there are still some deficiencies in the research on the professional development of preschool teachers in China. First, the theoretical research on preschool teacher professional development is still shallow, and it still needs to learn from foreign research results. Second, the professional standards of preschool teachers are not strong adaptability, whose operability is still needed to improve. Third, there is a lack of empirical basis for research on influencing factors of preschool teachers' professional development; it is urgent to strengthen quantitative research. Fourth, the strategy research of preschool teachers' professional development lacks practicality, so it is urgent to enhance the effectiveness of research.
\end{abstract}

\section{Subject Areas}

Education

\section{Keywords}

China, Preschool Teacher, Professional Development, Research Review 


\section{Introduction}

Since the emergence of division of labor and various occupations in human society, the difference between high and low status among occupations has become a common phenomenon in human society. With the industrial revolution and the development of knowledge and technology, the social division of labor has become increasingly sophisticated, and various emerging professions have emerged, many of which can win the title of "professional". So, what is professional? In 1933, sociologists Carl Saunders and Wilson defined "professional" for the first time in their classic book "ProfessionaP". They think that the so-called professional refers to a kind of profession that requires special technology which a group of people works in. It is a profession that requires special intelligence to cultivate and complete, and its purpose is to provide specialized services [1]. In fact, whether in the minds of many western sociologists or in the eyes of the general public, the commonality of professional groups is very obvious. That is, as a professional, it must have three aspects: one is to have a set of "professional knowledge"; second, a professional autonomy; third, a "service ideal" or service or collective orientation. However, at present, the teaching profession cannot be called an "established profession", because the work of teachers is far from reaching a fully mature and established "professional" standard, so the teaching profession can only be a "marginal professional" or "semi-professional". Because of this, promoting teacher professionalization has always been the direction of all countries.

Since the establishment of modern teaching form-Class Teaching System, the movement of teacher specialization has gone through a history of 300 years. However, since the 1980s to now, the focus of teacher professionalization has changed, that is, it mainly starts from the role or practice of teachers to pay attention to teachers' professional development. This shift aims to establish the professional status of teachers, train teachers to meet professional standards, and promote the professional development of teachers, so as to improve the quality of teachers' education.

The preschool teacher professional development is a subordinate concept of teacher professional development and different researchers have different views on the connotation of it. Professor Gu, R. F. believes that the professional growth of preschool teachers mainly refers to the development process of preschool teachers from non-professionals to professionals and constantly improving their own professional quality [2]. Li, Y. J. believes that the professional development of preschool teachers is an activity procedure of continuous learning of professional knowledge, acquisition of professional skills and formation of good professional attitude by preschool teachers in order to achieve their professional development goals [3]. Chang, $\mathrm{H}$. believes that preschool teacher professional development refers to the process in which the preschool teachers gradually mature their teaching skills and educational literacy through personal efforts and collective training in their personal work [4]. Based on this, the study defines 
"preschool teacher professional development" as: through continuous learning and exploration, preschool teachers continuously strengthen their professional thoughts, professional knowledge, professional ability, professional psychology and other aspects. Make oneself from immature to mature gradually, also make oneself grow from novice teacher to expert teacher, the process that realizes self-development value finally.

In July 2001, the Ministry of Education of the People's Republic of China (MOE) issued the "Preschool Educational Guidance Outline (Trial)" (hereinafter referred to as the "Outline"), which clearly states that preschool education is an important part of basic education and is the cornerstone of school education and lifelong education in China. Among them, specific requirements have been made for the teaching of preschool teachers, and the professional development of preschool teachers has begun to be concerned. In December 2011, MOE issued "Professional Standards for Preschool Teachers (tria)" (hereinafter referred to as the "Standard"), which pointed out the direction and path for preschool teachers' professional development. Since the promulgation of "Outline" and "Standard", preschool teachers' professional development research have been after more than ten years, during this period, preschool teachers' professional development related research fruitful, the necessary sorting, induction and comb, is conducive to a correct understanding and research to promote the development of preschool teachers' professional along a scientific and rational direction. In recent years, National documents related to Preschool education such as "Outline" (2001) and "Notice on the Implementation of the National Training Plan for Preschool Teachers" (2011) have been gradually implemented, ushering in an unprecedented bright future for Preschool education in China. As for the stage of promoting preschool education, the main problems that need to be solved are the small scale and insufficient capacity of preschools, "Difficult to enter the preschool", "Expensive to enter the preschool" and other perennial difficult problems. However, with the increasing investment of the state and society, these perennial difficult problems will be alleviated in the whole society. Teacher education reform is the key link of the development of educational business, and teachers are the key factor of this key link. At present, with the turn of social contradictions and the improvement of people's living standards, the requirements for preschool education quality are getting higher and higher, and the key factor to improve the quality of preschool education is the improvement of the quality of preschool teachers team. Therefore, this study generally sorts out and summarizes relevant researches on the professional development of preschool teachers in China, hoping to have a more objective and comprehensive understanding of the research status of the professional development of preschool teachers.

\section{Research Samples and Research Methods}

\subsection{Research Samples}

Since "preschool teacher", "preschool teacher" and "pre-school teacher" all refer 
to the same occupation, after the author respectively searches these keywords, they are unified and standardized as "preschool teacher" in the final data sorting. The data of this study were obtained from China National Knowledge Infrastructure (CNKI). An accurate matching search was conducted with the literature title "preschool teacher" and "professional" or "kindergarten teacher" and "professional" or "pre-school teacher" and "professional", and a total of 725 literatures were retrieved. After screening and eliminating repetitive papers and non-academic papers (no author, brief introduction, interview materials, conference notice, technical promotion, newspaper publicity, etc.), a total of 631 effective research samples were obtained. The data download date was December 31, 2018. Among them, 520 journal papers, 1 doctoral thesis, 110 master's thesis.

\subsection{Research Methods}

This study uses a combination of bibliometric analysis and content analysis. According to the 631 effective research sample literatures, the paper analyzes the time, quantity, source, type and research subjects of the publication, in order to comprehensively and deeply understand the research status of the professional development of Chinese preschool teachers. And to grasp the current research hotspots and core issues of the professional development of preschool teachers in China.

\section{Analysis of Research Status}

\subsection{Quantitative Analysis}

\subsubsection{Literature Publication Time and Quantity Analysis}

From the research sample literature, the earliest literature on preschool teachers' professional development (or kindergarten teachers' professional development or pre-school teachers' professional development) that can be retrieved in CNKI is the paper titled "Research Learning and Preschool Teachers' Professional Development" published by Peng, Q. F. in the Chinese core journal Studies in Early Childhood Education in 2002. Subsequent research showed a breakpoint in 2003, but from 2004 there has been a trend of gradual fluctuating upward, indicating the existence of continuous research. And in 2011, there was a research small peak, with the number of research articles reaching 46. However, in 2012, there was a short decline, and then it began to rise again, with the number of published articles remaining above 66. In the effective research sample literature, there are 1 doctoral thesis and 91 master's thesis. Among them, the doctoral thesis appeared in 2015. Although the master's thesis began to appear in 2004, it did not begin to show a rising trend of fluctuating upward until 2010. The time and quantity of literature publication are detailed in Figure 1. Through research and analysis can know that: 1) China's research on the professional development of preschool teachers started late, the degree of attention is insufficient, and the research progress is slow. 2) Since 2010, with the introduction of documents from the Ministry of Education, such as "Some Opinions of the State Council on the 


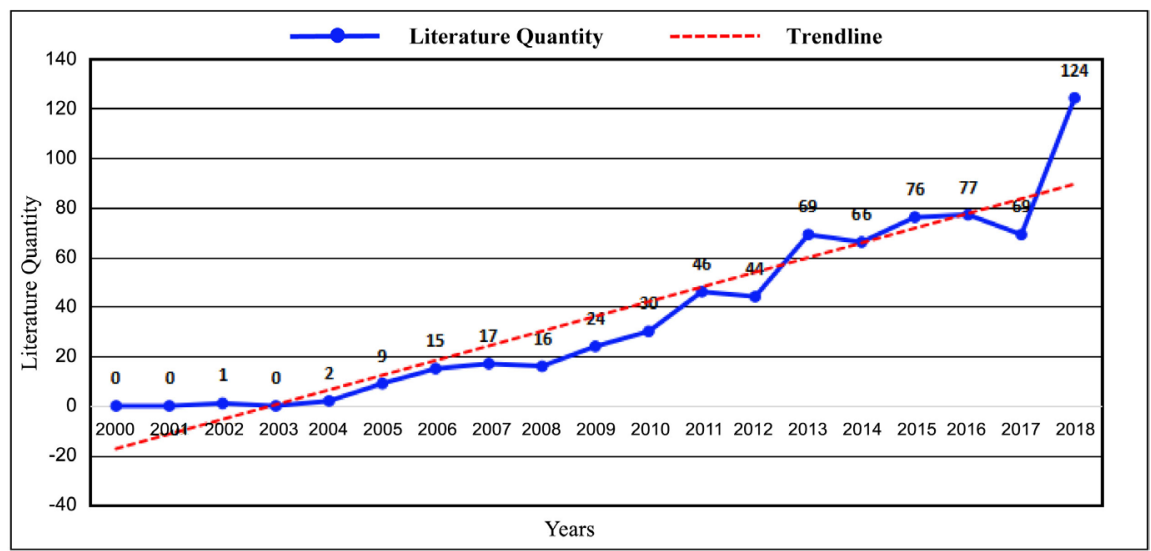

Figure 1. Annual distribution of sample size.

Current Development of Preschool Education" and "Notice of the Ministry of Finance of the Ministry of Education on the Implementation of the National Training Plan for Preschool Teachers", the amount of literatures has risen sharply, indicating that the introduction of relevant policies by the state will increase the level of concern of researchers in this field.

\subsubsection{Literature Source and Type Analysis}

In a sample of 631 valid studies, 520 journal papers accounted for $82.41 \%$ of the total sample data, mainly published in Journal of Educational Development, Studies in Early Childhood Education, Journal of Southwest University, Early Childhood Education and other publications. It can be analyzed that: 1) The national education core journals have paid close attention to the research work of preschool teachers' professional development for a long time. The researchers in the national education field are the backbone power of the professional development research of preschool teachers in China, and also play a certain leading role. 2) The research level and quality of the professional development of preschool teachers need to be further improved. According to research statistics, the number of documents published in core journals is only 80 , accounting for only $15.38 \%$ of the total number of journal articles in the research sample. And the 111 excellent master and doctoral thesis accounted for only $17.59 \%$ of the total sample of the study. Among them, 58 authors are Preschool Education (professional degree), 13 authors are Preschool Pedagogy. And the other authors come from Principle of Pedagogy, Curriculum and Teaching Methodology, Comparative Education, Educational Economy and Management, Foreign Languages and Literatures, Pedagogy, Higher Education and other different professions. It can be seen that the colleges and universities have formed a relatively stable and continuous research team for the development of preschool teachers' professional development, and their research perspective has a certain discipline background, but also has $77.17 \%$ of the researchers still study from the perspective of ordinary universities to research the basic problems of the professional development of preschool teachers and the lack of systematic research on the professional de- 
velopment of preschool teachers.

\subsection{Content Analysis}

\subsubsection{Research Subject Perspective Analysis}

Through sorting out, it is found that 631 effective research sample literatures come from 342 schools. Due to the limitation of space, this paper mainly intercepts the publishing schools with the number of literatures above 3 and ranking in the top 18. The main research subjects and the number of published articles are shown in Table 1. Among them, Education College of Baoji Arts and Sciences University, Education College of Guangzhou University, Education Science and Management College of Yunnan Normal University, Inner Mongolia National Preschool Normal Higher Learning Junior College and Education Department of Southwest University, as high-yield publishing institutions in this field, have published 27 articles so far, with a cumulative percentage of $6.18 \%$.

\subsubsection{Research Topic Content Analysis}

According to the key elements of preschool teachers' professional development and the specific content of the research on preschool teachers' professional development in China, the author focuses the research topic on four aspects: First,

Table 1. The literature quantity situation of research subject (Partial).

\begin{tabular}{|c|c|c|}
\hline Number & Research Subject & $\begin{array}{l}\text { Literature } \\
\text { Quantity }\end{array}$ \\
\hline 1 & Education College of Baoji Arts and Sciences University & 7 \\
\hline 2 & Education College of Guangzhou University & 5 \\
\hline 3 & Education Science and Management College of Yunnan Normal University & 5 \\
\hline 4 & Inner Mongolia National Preschool Normal Higher Learning Junior College & 5 \\
\hline 5 & Education Department of Southwest University & 5 \\
\hline 6 & Education College of Northwest Normal University & 4 \\
\hline 7 & Educational Science College of Nanjing Normal University & 4 \\
\hline 8 & Education Department of Northeast Normal University & 4 \\
\hline 9 & Educational Science Department of Qiannan Normal College for Nationalities & 4 \\
\hline 10 & Hangzhou Kindergarten Normal College of Zhejiang Normal University & 3 \\
\hline 11 & Qiannan Normal College for Nationalities & 3 \\
\hline 12 & Kunshan Jinhua Kindergarten & 3 \\
\hline 13 & Education College of Hebei University & 3 \\
\hline 14 & $\begin{array}{l}\text { School of Preschool Education and Special Education of East China Normal } \\
\text { University }\end{array}$ & 3 \\
\hline 15 & Ningbo Education College & 3 \\
\hline 16 & Education College of Southwest University & 3 \\
\hline 17 & Education College of Central China Normal University & 3 \\
\hline 18 & Guangxi Preschool Normal Higher Learning Junior College & 3 \\
\hline
\end{tabular}


the research on the connotation of preschool teachers' professional development. Second, the research on the professional standards of preschool teachers. Third, the research on the influencing factors of preschool teachers' professional development. Fourth, the research on preschool teachers' professional development strategies.

- Research on the Connotation of Preschool Teachers' Professional Development

After consulting the relevant literature, it is found that the definition of the concept of "preschool teacher professional development", in terms of the existing research results, involves many concepts such as "kindergarten teacher professional development", "preschool teacher specialization", "preschool teacher professional growth". And different scholars study from different dimensions has different definitions, it can be said that the benevolent see benevolence and the wise see wisdom.

Ye, L. et al. (2001) define "teacher professional development" as the process of teacher's professional growth or the continuous updating, evolution and enrichment of the teacher's internal professional structure [5]. Hu, H. Y. (2004) starts from the characteristics of teachers' professional knowledge structure and believes that the professional development of preschool teachers must include the knowledge of educators, the knowledge of learners, the knowledge of educational media, the organize knowledge of educational activities and other ascension of professional knowledge [6]. Xu, X. L. (2008) defines the professional development of preschool teachers from an ecological perspective and defines it as a process. It refers to the preschool teachers' active acquisition of the expertise and skills of early childhood teaching, and internalizes the preschool education norms, and finally forms the professionalism of preschool education, showing professional autonomy and realizing professional responsibility [7]. Gan, Z. Y. (2012), based on the understanding of "autonomy", believes that teachers' professional development should lay down feasible goals suitable for their own professional development on the premise of emphasizing teachers' self-consciousness and initiative, so as to improve their educational and teaching abilities and ultimately transform their roles [8]. Yu, F. (2015) understood "professional development of preschool teachers" as a process by which preschool teachers develop their professional concepts, professional knowledge and professional abilities from novice level to expert-type teacher or educator level through continuous learning, and finally realize independent professional development [9].

Based on the above analysis, the academic community has reached a certain consensus on the connotation of "preschool teacher professional development", which is mainly summarized into five levels: the first level is consciousness, including professional concept and professional cognition and so on. The second is the emotional level, including professional feelings, professional attitude and so on. The third is the moral level, including professional ethics, professional norms and so on. Fourth, the level of knowledge and skills, including profes- 
sional knowledge, professional skills and so on. Fifth, professional ability, including teaching ability, reflective ability, etc. Some scholars also put forward some different views, such as Yang, M. C. (2008), indicating that the professional development of preschool teachers should be professional, independent, self-consciousness and lifelong, which should not be a static indicator, but a dynamic lifelong process [10]. Jiang, Y. (2015) believes that to understand the connotation of preschool teachers' professional development, the researchers should not only start from the three dimensions of "Concept", "Attainment" and "Action", but also pay attention to the "Spiritual" growth of preschool teachers [11]. Wang, S. (2017) believe that the professional development of preschool teachers is also a process by which preschool teachers, as learning subjects in the new era, can consciously, proactively and sustainably construct their own educational concepts and adjust their educational behaviors, and gradually reach the standards of preschool teachers [12].

- Research on Professional Standards of Preschool Teachers

"Professional Standards for Preschool Teachers (trial)" (2012) is the basic requirement for preschool teachers' professional quality in China, the basic standard for teachers to implement education and teaching behaviors, and the basic criterion to guide teachers' professional development, as well as the important basis for teachers' cultivation, admittance, training and assessment [13].

By reading the literature, it can be found that Yi, L. Y. (2008) believes that China can borrow the professional standards of preschool teachers in the United States. The professional development requirements of excellent preschool teachers proposed by the National Board for Professional Teaching Standards (NBPTS) in the United States also portray a beautiful blueprint for the professional standards of excellent preschool teachers in other countries, which is worth our reference [14]. But Peng, B. et al. (2011) believe that China can learn from the experience of western developed countries, but should draw on the experience of many countries and should not be marked by a certain country [15]. Shen, J. Z. (2015) in the "Professional Development of Preschool Teachers" book, that although the professional standards of preschool teachers in different countries have their own characteristics, but their core content and requirements coincide, have a high degree of unity [16], worthy of China multi-faceted reference and learning.

Through research literature, it is found that although China has introduced "Professional Standards for Preschool Teachers (trial)" (2012), the academic community is studying the operability and adaptability of the document on the one hand, and on the other hand In the study of whether it should be based on the professional standards of developed countries in the West. However, some scholars believe that the professional standards of preschool teachers should be studied from the perspective of China's own national conditions. For example, Yang, W. (2012) believe that the current classification of preschool teachers' professional development stage emphasizes not only the external standards of 
preschool teachers, but also the unity and pattern of professional standards, resulting in serious neglect of consideration of the internal continuity and individual differences of preschool teachers [17]. Yang, F. L., \& Zhang, Y. (2014) believe that the professional development of preschool teachers should be the key goal in the professional standards of preschool teachers [18]. Therefore, the author believes that the compilation and implementation of professional standards for preschool teachers in China must not copy the professional standards of other countries, but should be combined with the actual situation of our country, have some choices, adopt appropriate methods to formulate professional standards for preschool teachers with Chinese characteristics.

- Research on Influencing Factors of Preschool Teachers' Professional Development

All the time, the research on the influencing factors of preschool teachers' professional development has been a hot topic in academic circles, and the number of achievements accounts for about $38.10 \%$ of the research achievements of preschool teachers' professional development. Generally speaking, the study of "influencing factors" is an indispensable key factor to understand the overall "internal mechanism".

Yang, X. P., \& Yin, J. (2005) pointed out that factors affecting preschool teachers' professional development could be analyzed from three aspects, including the characteristics of kindergarten school-based curriculum, personnel factors and teacher culture [19]. Zhai, Y. (2006) pointed out that the influence of professional identity of preschool teachers on professional development can be analyzed from the perspectives of self-image, professional preparation, work motivation, teaching practice and future prospect [20]. Chen, J. J. (2007) clearly pointed out that there was a certain degree of correlation between kindergarten environmental factors and preschool teachers' professional development. Among them, the organizational atmosphere, rules and regulations of kindergarten and teacher culture have a direct impact on teacher professional development [21]. Zhou, X. (2009) pointed out that subject status of preschool education, kindergarten strength, pre-service education, induction assessment, on-the-job training, and professional identity are important factors affecting the professional development of preschool teachers [22]. Ji, H. H. (2010) showed that teachers' personal background, implicit factors, kindergarten material and spiritual environment factors and interpersonal support factors all had significant influences on preschool teachers' professional development [23].

Based on the above analysis, it can be concluded that the current academic researches on the influencing factors of preschool teachers' professional development are mainly reflected in two aspects. One is the internal factors of individual teachers. It mainly includes teachers' own education background, teaching age, salary, family factors, professional identity, professional quality, teaching practice, self-development awareness, self-promotion motivation, etc. The second is the external factors of the individual teacher. It mainly includes the social recog- 
nition of the preschool teachers' profession, the attention of kindergartens to the professional development of preschool teachers, the kindergarten-based culture, the preschool education management system, pre-service education, on-the-job training, and post-employment training, etc. These factors are closely related to the professional development of preschool teachers, and even "A slight move in one part may affect the situation as a whole".

- Research on Professional Development Strategies of Preschool Teachers

As far as the path and method are concerned, not only the research to solve practical problems, but also the indispensable research in the field of practice. According to the research findings, the research results of the professional development path and mode of preschool teachers also account for the largest proportion in the whole preschool teacher professional development research result, accounting for about $42.04 \%$.

By searching the literature, Song, S. T. (2008) showed that the professional development level of preschool teachers should be improved from the professional quality and management of preschool teachers [24]. Zhou, X. (2009) believes that the three major dimensions of the macro level (national), the meso level (kindergarten), and the micro level (preschool teachers) should be taken together to promote the countermeasure problem of the professional development of preschool teachers [22]. Chen, S. (2010) proposed that educational administrative units, teacher training institutions, kindergartens and teachers should perform their respective duties, so as to form a joint effort to promote the professional development of preschool teachers [25]. Deng, Z. J. (2014) pointed out that various kindergartens should choose targeted and creative promotion strategies based on the characteristics of their own kindergarten management system, so as to promote the professional development of preschool teachers [26]. Patiman, C. (2014) argues that the development and improvement of preschool teachers' professional development should start from the level of government and educational authorities, the level of kindergarten organization and culture, and the level of individual teachers [27]. Yan, H. (2017) combs and constructs six main paths of professional development: self-development internal drive, kindergarten-based support, expert team, post-employment training, funding guarantee, policies and regulations [28].

According to the existing research results, the academic research on the professional development path and mode of preschool teachers can be divided into three dimensions. Dimension 1: National Level. This includes formulating relevant policies, strengthening the emphasis extent on preschool teachers, and improving the social status of preschool teachers, etc. Dimension 2: Kindergarten Level. Including kindergarten-based training, teacher management, kindergarten-based teaching and research, etc. Dimension 3: Preschool Teacher Level. This includes improving self-development awareness, strengthening the ability of reflection in education and teaching, and improving the level of academic research, etc. 


\section{Reflections and Prospects of Research Results}

Through sorting out, analyzing and summarizing the existing literature, Chinese scholars have put the exploration of preschool teachers' professional development from theory into practice, and tested the theory in practice to sublimate the theory. Whether it is theoretical research or practical research, researchers have made a lot of gains. At present, the research results on the professional development of preschool teachers in China are not only significantly improved in terms of quantity, but also obvious safeguard in terms of quality. However, compared with western developed countries, China's research on the professional development of preschool teachers is still in its preliminary stage, no matter in terms of the research process, research stage or existing professional development level. In addition, compared with the existing professional development level of preschool teachers in western developed countries, the existing professional development level of preschool teachers in China still has great room for progress.

To sum up, first of all, the research on the professional development of preschool teachers in China is still shallow, and it is still necessary to learn from the relevant research results of foreign countries, so as to learn from each other and strive for perfection. Second, the promotion and implementation of China's relevant policy documents such as "Professional Standards for Preschool Teachers (trial)" needs to be improved, especially its operability. Third, the research on the professional development of Chinese preschool teachers lacks an empirical foundation in exploring the influencing factors, and it is urgent to strengthen relevant quantitative research. Last but not least, the strategy research on the professional development of Chinese preschool teachers is lack of practice, and it is urgent to enhance the relevant effectiveness research.

\section{Acknowledgements}

This research was supported by Research Achievements of the Graduate Innovation Fund Project of Gannan Normal University in Jiangxi Province, China (2018) "Empirical Study on the Influence of Teachers' Autonomous Support and Family Education on Children's Learning Quality"(Project No. YCX18A010), Jiangxi University Humanities and Social Sciences Research Project (2018) "Study on the Present Situation of Preschool Teacher Education Development and Quality Assurance Mechanism" (Project No. JY18119), China's Jiangxi Province Education Science Planning Project "Research on the Status and Cultivation of Left-behind Children's Learning Quality” (Project No. 17YB169).

\section{Conflicts of Interest}

The authors declare no conflicts of interest regarding the publication of this paper.

\section{References}

[1] Taipei Teachers Education Society (1992) Teacher Profession. Shuyuan Publishing 
House of Taiwan Normal University, Taipei.

[2] Zhang, S.Y. and Gu, R.F. (2013) Study on Professional Stages of Kindergarten Teachers from the Perspective of Teachers' Concerns. Studies in Early Childhood Education, 4, 57-63.

[3] Li, Y.J. (2010) Professional Development of Preschool Teachers from the Perspective of Constructivism. Education Exploration, 4, 93-94. http://www.wanfangdata.com.cn/details/detail.do?_type=perio\&id=jyts201004041

[4] Chang, H. (2004) The Tentative Analysis of Humanism Tropism on Children's Education Courses at the Present Time. Studies in Early Childhood Education, 5, 8-10.

[5] Ye, L., Bai, Y.M., Wang, D. and Tao, Z.Q. (2001) A New Probe into the Role of Teachers and Teacher Development. Educational Science Publishing House, Beijing, 226.

[6] Hu, H.Y. (2004) On the Professional Development of Preschool Teachers. Shanghai Research on Education, 10, 67-68.

[7] Xu, X.L. (2008) Research on Preschool Teachers' Professional Development from the Perspective of Ecology. Master's Thesis, Shandong Normal University, Jinan. http://kns.cnki.net/kns/brief/result.aspx?dbPrefix=SCDB

[8] Gan, Z.Y. (2012) The Footprint of Growth-A Narrative Study on the Self-Determination Professional Development of a Rural Kindergarten Teacher. Master's Thesis, Southwest University, Chongqing.

[9] Yu, F. (2015) Research on Professional Development of Preschool Teachers Supported by Information Technology-Take the Kindergarten-Based Teaching Research of Information Technology Support "Observation and Evaluation of Children's Mathematics Learning” as an Example. PhD Thesis, East China Normal University, Shanghai. http://kns.cnki.net/kns/brief/result.aspx?dbPrefix=SCDB

[10] Yang, M.C. (2008) Topic Research and Preschool Teachers' Professional Development-A Case Study of K Kindergarten in Lanzhou. Master's Thesis, Northwest Normal University, Gansu.

[11] Jiang, Y. (2015) Professional Development of Kindergarten Teachers Higher Education Press, Beijing, 34-36.

[12] Wang, S. (2017) Research on Current Situation and Promotion Strategies of Kindergarten Teachers' Professional Development in Nanshan District of Shenzhen City. Master's Thesis, Shenzhen University, Shenzhen. http://cdmd.cnki.com.cn/Article/CDMD-10590-1017812131.htm

[13] The Ministry of Education of the People's Republic of China (2012) Notice Concerning the Issuance of "Professional Standards for Kindergarten Teachers (Trial)", "Professional Standards for Primary School Teachers (Trial)" and "Professional Standards for Middle School Teachers (Trial)". http://www.moe.gov.cn/srcsite/A10/s6991/201209/t20120913_145603.html

[14] Yi, L.Y. (2008) American Professional Standards for Excellent Preschool Teachers and Its Enlightenment. Studies in Early Childhood Education, 10, 42-46.

[15] Peng, B., Di, A.N. and Lu, C.S. (2011) Exploration and Consideration of Regional Professional Standards for Preschool Teachers-Taking the Compilation of Professional Standards for Preschool Teachers in Wuhan as an Example. Studies in Early Childhood Education, 3, 25-29.

[16] Shen, J.Z. (2015) Professional Development of Kindergarten Teachers. Beijing Normal University Press, Beijing, 14. 
[17] Yang, W. (2012) The Problems Existing in Division of the Early Childhood Teachers' Professional Development and Its Response. Studies in Early Childhood Education, 8, 58-60.

[18] Yang, F.L. and Zhang, Y. (2014) The Role of Preschool Teacher under the Positioning of "Professional Standards for Kindergarten Teachers". Education Exploration, 8, 101-102. http://www.cqvip.com/QK/80055X/201408/661912975.html

[19] Yang, X.P. and Yin, J. (2005) Analysis on the Factors Affecting the Professional Development of Preschool Teachers in the Development of School-Based Curriculum. Studies in Early Childhood Education, 4, 49-51.

[20] Zhai, Y. (2006) View on the Influential Factors of Teacher Professional Development from Preschool Teacher Professional Identity. Studies in Early Childhood Education, 11, 39-41.

[21] Chen, J.J. (2007) A Study on the Kindergarten Environmental Factors Affecting Preschool Teachers' Professional Development. Master's Thesis, Guangzhou University, Guangzhou.

http://www.wanfangdata.com.cn/details/detail.do?_type=degree\&id=Y1160935

[22] Zhou, X. (2009) Preschool Teachers' Professional Development: Problems and Countermeasures. Master's Thesis, Jiangnan University, Wuxi. http://cdmd.cnki.com.cn/Article/CDMD-10295-2009250438.htm

[23] Ji, H.H. (2010) A Study on the Motivation of Preschool Teachers' Professional Development and Its Influencing Factors-A Case Study of Some Preschool Teachers in Henan Province. Master's Thesis, Henan University, Zhengzhou. http://cdmd.cnki.com.cn/Article/CDMD-10475-2010154887.htm

[24] Song, S.T. (2008) Current Situation and Countermeasure of Preschool Teachers' Professional Development in Ethnic Minority Areas. Master's Thesis, Southwest University, Chongqing. http://cdmd.cnki.com.cn/Article/CDMD-10635-2008092666.htm

[25] Chen, S. (2010) A Study on the Ways of Professional Development of Rural Preschool Teachers in Central China-A Case Study of Changyuan County, Henan Province. Master's Thesis, Hunan Normal University, Changsha. http://cdmd.cnki.com.cn/Article/CDMD-10542-2010126905.htm

[26] Deng, Z.J. (2014) Classified Promotion Strategies of Preschool Teachers' Professional Development Based on Different Kindergarten Running Systems. Journal of the Chinese Society of Education, 5, 91-94.

[27] Patiman, C. (2014) Current Situation, Problems and Countermeasures of Preschool Teachers' Professional Development in Urumqi. Master's Thesis, Shaanxi Normal University, Xi'an.

http://xueshu.baidu.com/usercenter/paper/show?paperid=e5c044d3b22a645d850f82 e52bbb9d38\&site=xueshu_se\&hitarticle $=1$

[28] Yan, H. (2017) Research on the Professional Development Path of Non-Compiled Preschool Teachers-Taking Z District of Ningbo City as an Example. Master's Thesis, Ningbo University, Ningbo.

http://xueshu.baidu.com/usercenter/paper/show?paperid=29d217bf748607ecf1e81ff e59c8d494\&site=xueshu_se 